Original Research Article

\title{
Effect of fenofibrate on acute and subacute inflammation in male Wistar rats
}

\author{
Serah Johny ${ }^{1 *}$, Torgal S. S. ${ }^{2}$, Ramesh C. ${ }^{3}$, Anna Mathew ${ }^{1}$
}

${ }^{1}$ Department of Pharmacology, MOSC Medical College,

Kolenchery, Ernakulam, Kerala, India

${ }^{2}$ Department of Pharmacology,

${ }^{3}$ Department of Pathology, KLE University's J.N. Medical College, Belgaum, Karnataka, India

Received: 03 September 2018 Accepted: 27 September 2018

*Correspondence to:

Dr. Serah Johny,

Email: serahjohny@gmail.com

Copyright: (C) the author(s), publisher and licensee Medip Academy. This is an openaccess article distributed under the terms of the Creative Commons Attribution NonCommercial License, which permits unrestricted noncommercial use, distribution, and reproduction in any medium, provided the original work is properly cited.

\begin{abstract}
Background: The objective of the study was to investigate the effect of fenofibrate on acute and subacute models of inflammation in adult male Wistar rats.

Methods: After obtaining clearance from Institutional Animal Ethics Committee, six adult male Wistar rats were allocated to each of the three groups i.e. control, aspirin and fenofibrate. Acute inflammation was studied using carrageenan induced rat paw oedema and the volume displacement due to paw oedema was measured using the plethysmograph. Subacute inflammation was studied using foreign body insertion (cotton pellet and grass pith) models. Dry granuloma weight and histopathological examination of the granuloma were the outcome measures for measuring subacute inflammation. The percentage inhibition of inflammation with aspirin and fenofibrate was calculated in both acute and subacute models. The experiments were conducted according to the guidelines of the Committee for the Purpose of Control and Supervision on Experiments on Animals (CPCSEA). The mean volume displacement obtained with a plethysmograph, the mean dry weight of granuloma and the percentage inhibition with aspirin and fenofibrate were analyzed by one way analysis of variance (ANOVA) using Graph pad prism software.

Results: Aspirin and fenofibrate significantly reduced both acute and subacute inflammation $(p<0.001)$. Dunnet's test showed a significant difference in the study groups when compared to the control. The reduction of inflammation with fenofibrate was comparable to aspirin.

Conclusions: Oral fenofibrate showed significant anti-inflammatory activity, which was comparable to aspirin, in both acute as well as sub-acute models of inflammation. This anti-inflammatory effect may benefit atherosclerosis in patients receiving fenofibrate for hyperlipidemia.
\end{abstract}

Keywords: Fenofibrate, Inflammation, Wistar rats

\section{INTRODUCTION}

Atherosclerosis remains the major cause of premature disability and death in developed societies. Current predictions estimate that by the year 2020 cardiovascular diseases, notably atherosclerosis, will become the leading global cause of total disease burden. ${ }^{1}$ Well-established risk factors for atherosclerosis include hypertension, dyslipidemia, and diabetes mellitus. More recent work reveals that procoagulant and proinflammatory states can be added as important contributors to the development of atherosclerosis..$^{2-4}$

This evolving view of atherosclerosis as a metabolic complication has directed attention towards peroxisome proliferators-activated receptors (PPARs), a transcriptional regulator involved in lipid metabolism. Activation of PPAR $\alpha$ has been reported to improve levels 
of triglycerides, high density lipoprotein (HDL), and the overall atherogenic plasma lipid profile, while few studies also show that PPAR $\alpha$ potentially modulates inflammation. ${ }^{5}$

Fibrates are a class of cholesterol-lowering drugs that are thought to activate PPAR- $\alpha$. In vitro studies have shown that fibrates may have pleiotropic effects including the reduction of the inflammatory process at the level of vascular wall and in the plasma. ${ }^{6-8}$ These properties could be of additional benefit in atherosclerosis leading us to our research question how effective is fenofibrate in reducing inflammation in rat models of acute and sub-acute inflammation. Thus, this study was planned to evaluate the anti-inflammatory effect of oral fenofibrate on acute and sub acute models of inflammation in male Wistar rats in comparison to the control (1\% gum acacia) and aspirin.

\section{METHODS}

The study was approved by the Institutional Animal Ethics Committee (IAEC) constituted as per the guidelines of Committee for the Purpose of Control and Supervision of Experiments on Animals (CPCSEA), New Delhi.

Adult healthy male Wistar rats weighing $175 \pm 25$ grams were obtained from the central animal house and were acclimatized to $12: 12$ hour light - dark cycle for 10 days prior to the day of experimentation. They were maintained on standard rat chow pellet (Amrut Brand) and water ad libitum. Acute inflammation was produced by injecting carrageenan in the hind paw of Wistar rats and subacute inflammation by implanting foreign body subcutaneously as described below.

\section{Carrageenan induced rat paw oedema model ${ }^{9}$}

Adult male Wistar rats were divided into three groups of six each. They were fasted overnight with water ad libitum prior to the day of experiment. The control group received $0.5 \mathrm{ml}$ of $1 \%$ gum acacia suspension, orally, while the treatment groups received calculated clinically equivalent doses of fenofibrate or aspirin in $1 \%$ gum acacia suspension, orally. Aspirin was taken as the standard antiinflammatory drug.

Thirty minutes after aspirin and four hours after fenofibrate administration, $0.05 \mathrm{ml}$ of $1 \%$ carrageenan in normal saline was injected into the sub plantar region of one of the hind paws according to the technique of Winter et al. ${ }^{9}$ A mark was made on the leg at the malleolus to facilitate uniform dipping at subsequent readings. The paw volume in milli-litre was measured with the help of plethysmograph by mercury displacement method (Figure 1) at zero hour (immediately after injecting carrageenan). The same procedure was repeated at $0.5,1,3,4$ and 5 hours. The difference between 0 hour and subsequent reading was taken as actual paw oedema volume. The percentage inhibition of oedema in the various treated groups was then calculated by using the formula.
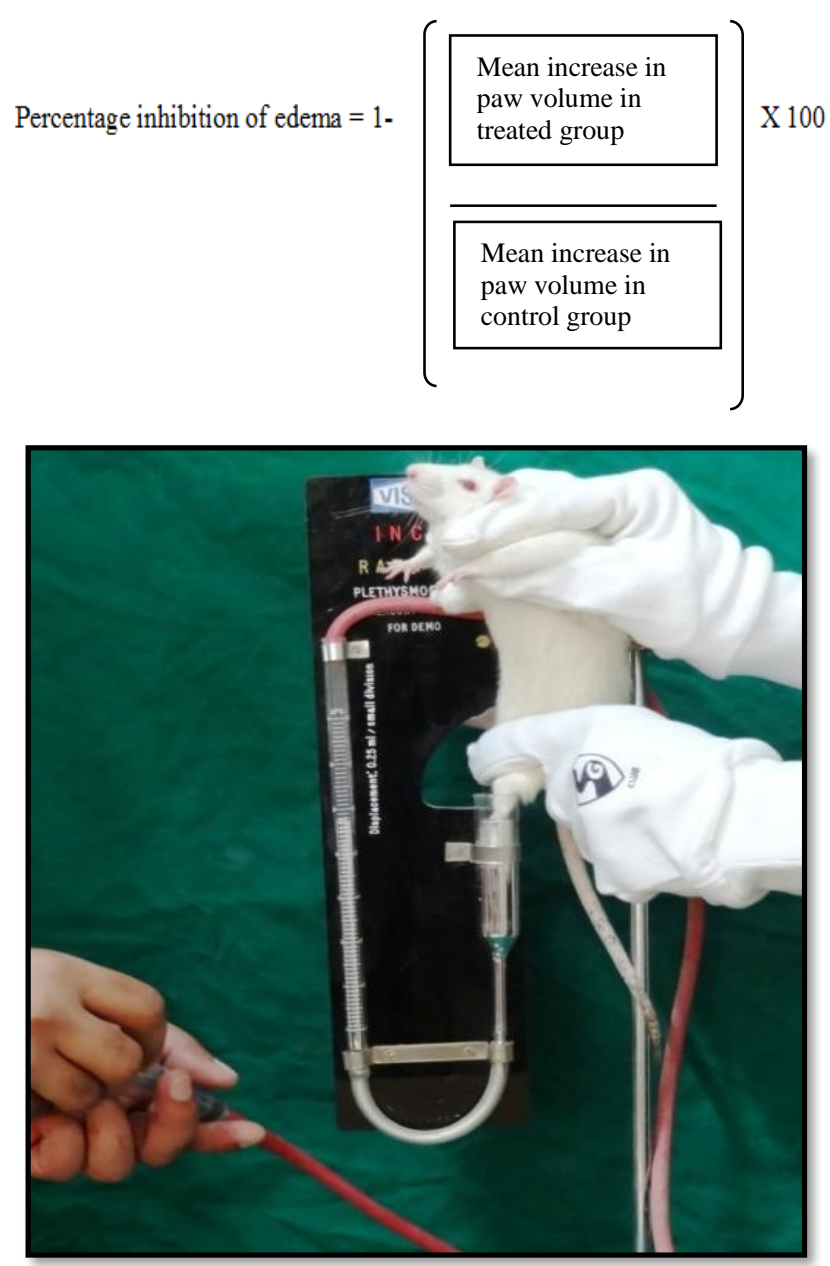

Volume displacement produced by rat paw oedema is measured on the plathysmograph and the percentage inhibition after administration of aspirin and fenofibrate is calculated

\section{Figure 1: Carrageenan induced paw oedema model} for acute inflammation.

\section{Foreign body induced granuloma model ${ }^{10}$}

Adult male Wistar rats were divided into three groups of six each. After clipping the hair in axillae and groin, under thiopentone anaesthesia, two sterile cotton pellets weighing $10 \mathrm{mg}$ each and two sterile grass piths ( $25 \times 2 \mathrm{~mm})$ were implanted randomly, subcutaneously, through a small incision (Figure 2). The wounds were then sutured and animals were caged individually after recovery from anaesthesia. Aseptic precautions were taken throughout the experiment. The treatment was started on the day of implantation and was repeated every twenty-four hours, regularly, for ten days.

On the eleventh day, the rats were sacrificed with an overdose of thiopentone anaesthesia to remove cotton pellets and grass piths (Figure 2). The grass piths were preserved in $10 \%$ formalin for histopathological studies. The pellets, free from extraneous tissue were dried overnight in the incubator at $60^{\circ} \mathrm{C}$ to note their dry weight. Net granuloma formation was calculated by subtracting initial weight of cotton pellet $(10 \mathrm{mg})$ from the weights 
noted. Mean granuloma dry weight for various groups was calculated and expressed as $\mathrm{mg} / 100 \mathrm{gm}$ body weight. The percentage inhibition of granuloma dry weight was calculated using formula.
Percentage inhibition of granuloma dry weight 1 -
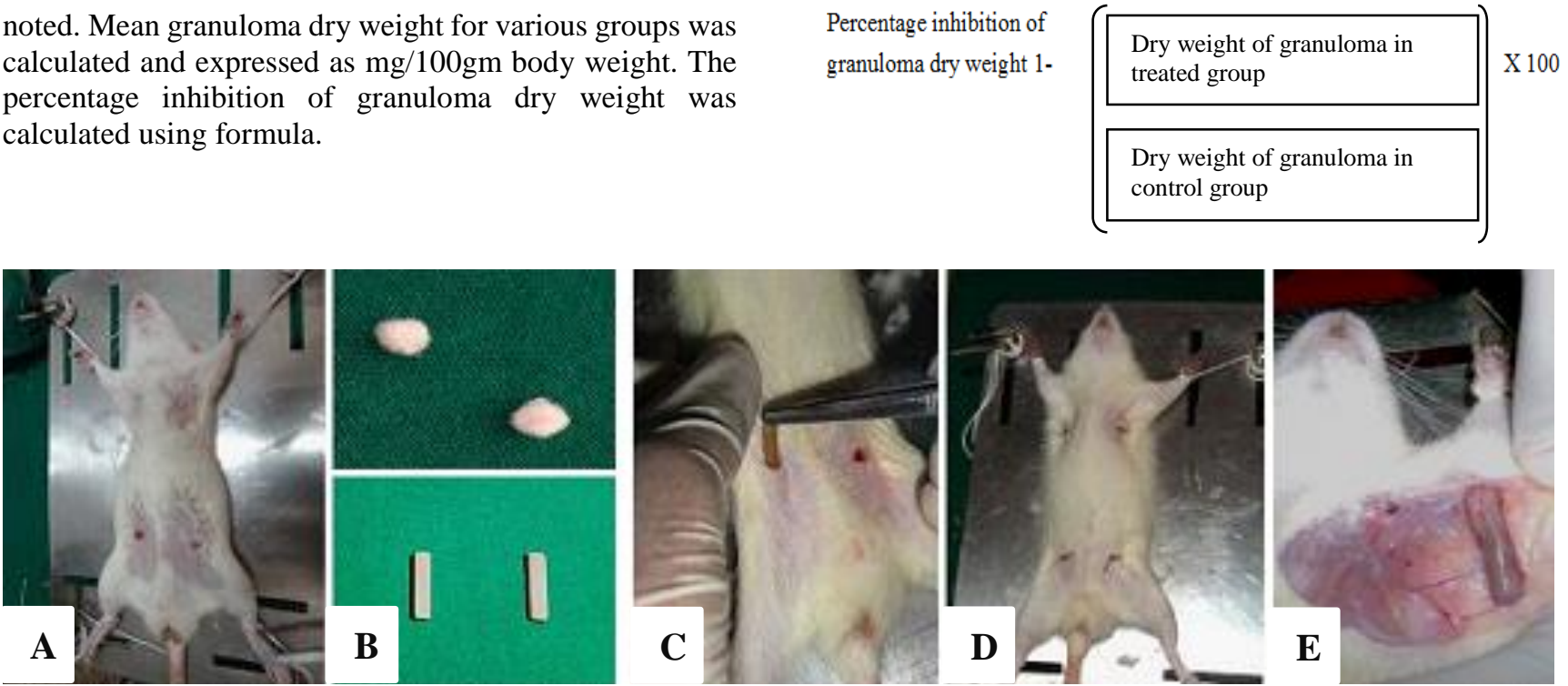

Cotton pellets are inserted in the axillary region and grass piths in the groin of Wistar rats.After 11 days the cotton pellets are removed, dried and weighed to obtain the granuloma dry weight. Histopathological examination of haematoxyllin and eosin stained sections of the grass pith granuloma is performed

Figure 2: (A to E) Foreign body insertion model for sub-acute inflamation.

The mean volume of displacement for each of the time intervals was obtained and the standard error of the mean (SEM) was obtained for each of the groups. The mean dry granuloma weight and SEM were also obtained.

The data was analysed by one way analysis of variance (ANOVA) followed by Dunnet's test to compare each group with control and Bonferroni's test to compare the aspirin and fenofibrate groups using Graph pad prism software and p-value $<0.05$ was considered significant.

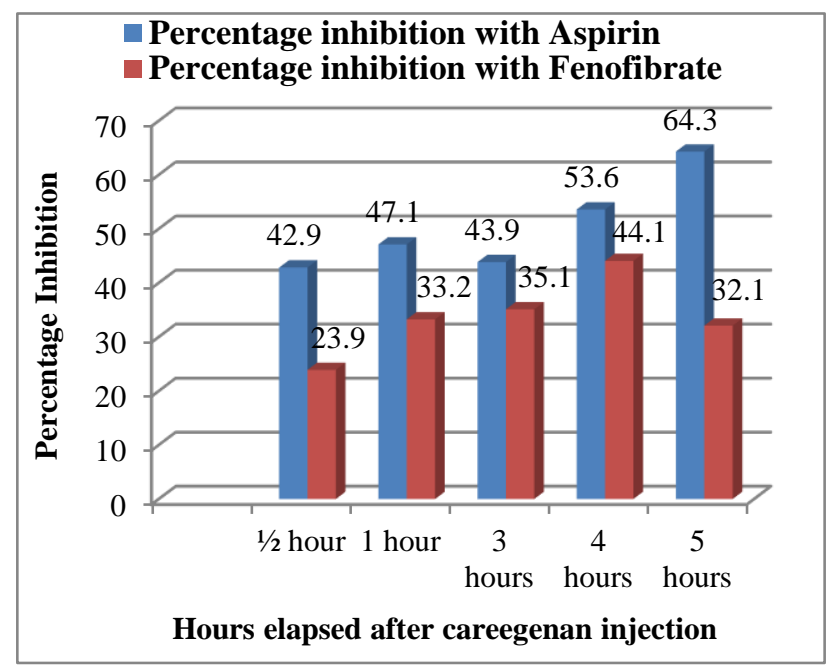

There was a significant difference in the percentage inhibition of paw oedema following carrageenan injection with aspirin and fenofibrate compared to the control $(\mathrm{p}<0.001)$

Figure 3: Percentage inhibition of carrageenan induced paw oedema with aspirin and fenofibrate.

\section{RESULTS}

\section{Carrageenan induced model for acute inflammation}

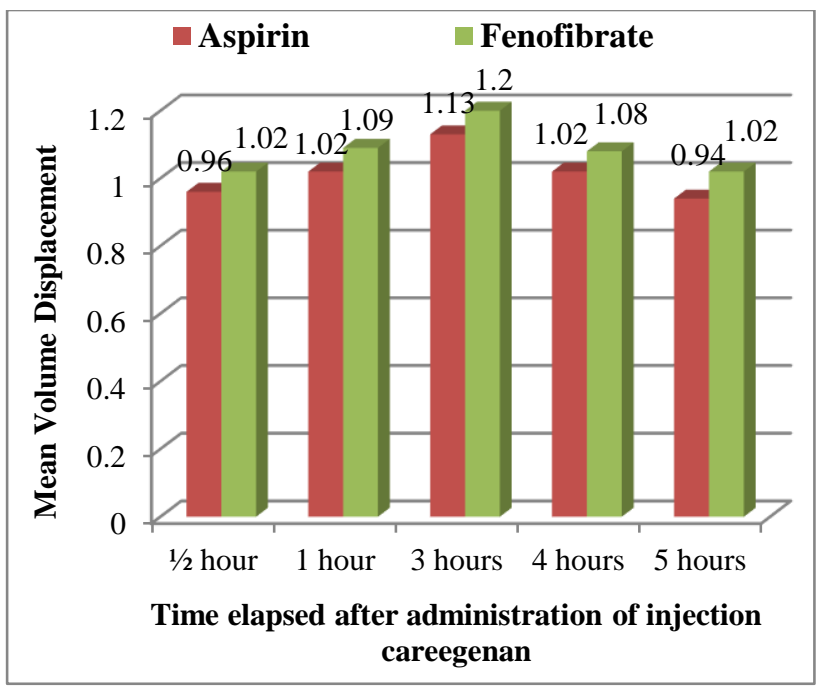

The reduction in paw oedema in the aspirin and fenofibrate groups was comparable, however there was no significant difference between the two groups ( $p>05)$

Figure 4: Comparison of reduction of paw oedema by aspirin and fenofibrate.

The mean paw oedema volume in milli-litres $(\mathrm{ml})$, as measured by mercury displacement using a plethysmograph, for control group, aspirin $(200 \mathrm{mg} / \mathrm{kg})$ group and fenofibrate $(36 \mathrm{mg} / \mathrm{kg})$ group at $0.5,1,3,4$ and 5 hours is shown in Table 1. The fenofibrate treated group showed significant inhibition $(\mathrm{p}<0.001)$ of paw oedema 
(Figure 3). These results clearly demonstrate the antiinflammatory activity of fenofibrate in the acute model of inflammation. Further the anti-inflammatory activity of fenofibrate was comparable with that of aspirin ( $p>0.05)$ as shown in Figure 4.

Table 1: Measurement of plethysmographic volume displacement of paw oedema in wistar rats.

\begin{tabular}{|c|c|c|c|c|}
\hline \multirow[b]{2}{*}{$\begin{array}{l}\text { Time after injection } \\
\text { of carrageenan }\end{array}$} & \multicolumn{3}{|c|}{ Volume displacement after injection of carageenan in ml (Mean \pm SEM) } & \multirow[b]{2}{*}{$\begin{array}{l}\text { ANOVA p- } \\
\text { value }\end{array}$} \\
\hline & $\begin{array}{l}\text { Control } \\
(0.5 \mathrm{ml} \text { gum acacia }-1 \%)\end{array}$ & $\begin{array}{l}\text { Aspirin } \\
(200 \mathrm{mg} / \mathrm{Kg})\end{array}$ & $\begin{array}{l}\text { Fenofibrate } \\
(36 \mathrm{mg} / \mathrm{Kg})\end{array}$ & \\
\hline $1 / 2$ hour & $1.150 \pm 0.02$ & $0.958 \pm 0.02$ & $1.017 \pm 0.02$ & $<0.001$ \\
\hline 1 hour & $1.275 \pm 0.025$ & $1.017 \pm 0.02$ & $1.092 \pm 0.02$ & $<0.001$ \\
\hline 3 hours & $1.450 \pm 0.02$ & $1.125 \pm 0.025$ & $1.2 \pm 0.022$ & $<0.001$ \\
\hline 4 hours & $1.317 \pm 0.016$ & $1.017 \pm 0.01$ & $1.083 \pm 0.016$ & $<0.001$ \\
\hline 5 hours & $1.208 \pm 0.02$ & $0.941 \pm 0.02$ & $1.017 \pm 0.0166$ & $<0.001$ \\
\hline
\end{tabular}

Post hoc analysis by Dunnet's Test revealed that plathysmographic volume displacement in Wistar rats with paw oedema after careegenan injection was significantly reduced after aspirin and fenofibrate administration compared to the control $(\mathrm{p}<0.001)$

Table 2: Mean granuloma dry weight and percentage inhibition two weeks after foreign body insertion in Wistar rats.

\begin{tabular}{|c|c|c|c|c|c|}
\hline Mean granuloma dry & ght in $\mathrm{mg} / 10$ & s $($ Mean \pm SE & Percentagc & ition $(\%)$ & \\
\hline $\begin{array}{l}\text { Control } \\
0.5 \mathrm{ml} \text { gum acacia }-1 \%\end{array}$ & $\begin{array}{l}\text { Aspirin } \\
\text { 200mg/Kg }\end{array}$ & $\begin{array}{l}\text { Fenofibrate } \\
36 \mathrm{mg} / \mathrm{Kg}\end{array}$ & $\begin{array}{l}\text { Aspirin } \\
\text { 200mg/Kg }\end{array}$ & $\begin{array}{l}\text { Fenofibrate } \\
\text { 36mg/Kg }\end{array}$ & $\begin{array}{l}\text { ANOVA } \\
\text { 'p' Value }\end{array}$ \\
\hline $17.40 \pm 0.582$ & $12.02 \pm 1.075$ & $12.81 \pm 0.358$ & 32 & 27.6 & $<0.001$ \\
\hline
\end{tabular}

Post hoc analysis by Bonferoni's Test revealed that mean granuloma dry weight in Wistar rats two weeks after insertion of foreign body (cottonpellets in axillae and grasspiths in groin) was comparable in rats administered aspirin and fenofibrate. However there was no significant difference betqween the two groups ( $>0.05)$

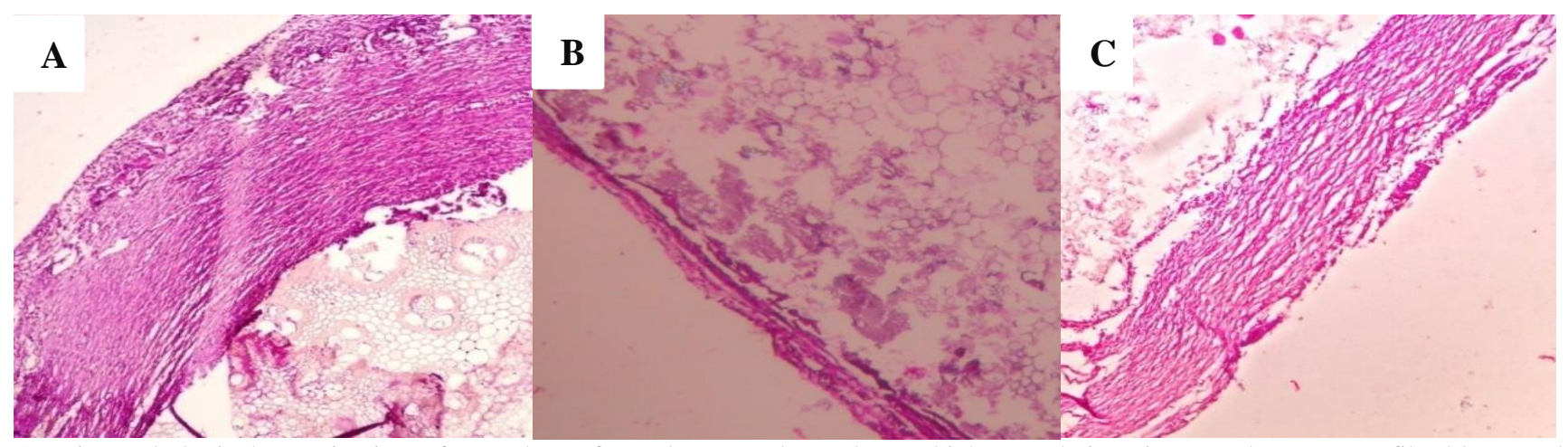

A) Histopathological examination of granuloma from the control rat shows thick granulation tissue and numerous fibroblasts and inflammatory cells. B, C) Markedly reduced granulation tissue, fibroblasts and inflammatory cells in granuloma from rats from the aspirin group and the fenofibrate group when compared to that of control group.

Figure 5: Grass pith granuloma (Haematoxyllin and Eosin at magnification X10); A) Control Group, B) Aspirin Group, C) Fenofibrate Group.

\section{Foreign body induced granuloma model for subacute inflammation}

The mean dry weight of ten days old granuloma, expressed as $\mathrm{mg}$ per $100 \mathrm{~g}$ body weight, in the control group was $17.70 \pm 0.58$, while in the aspirin treated group it was significantly decreased $(\mathrm{p}<0.01)$ with the mean value of $12.02 \pm 1.075$ and percentage inhibition of $32 \%$. Similarly, fenofibrate $(36 \mathrm{mg} / \mathrm{kg})$ treated group exhibited decreased granuloma weight $(\mathrm{P}<0.01)$ with mean value of
$12.81 \pm 0.358$ with percentage inhibition of $27.6 \%$ respectively (Table 2 ).

The anti-inflammatory activity of fenofibrate as observed in both, acute and sub acute studies was further confirmed by histopathological studies. The sections of grass pith when stained with haematoxylin and eosin showed granulation tissue which had acute inflammatory cells in dense sheets, densely scattered fibroblast and collagen in the control group, but revealed reduced number of 
fibroblasts, decreased granulation tissue, collagen content and fibrous tissue in aspirin and fenofibrate treated groups (Figure 5).

\section{DISCUSSION}

In this study, the hypolipidemic drug, fenofibrate was shown to have significant anti-inflammatory effect in both acute and subacute models of inflammation. Fibrates can slow the progression of atherosclerotic disease and decrease CVD morbidity. ${ }^{11}$ In addition to dyslipidemia, it is now appreciated that inflammation contributes to the development of atherosclerosis and its complications. The inflammatory response is a component of all forms of plaque. ${ }^{2,4}$ There exists a topographic relationship between inflammatory infiltrate, plaque rupture, and thrombosis. ${ }^{12}$ In dyslipidemic patients, low density lipoprotein (LDL) gets oxidised and results in the formation of foam cells. This modified LDL is chemotactic for other monocytes and up-regulates the expression of genes for macrophage colony stimulating factor and monocyte chemotactic protein (MCP) derived from endothelial cells. ${ }^{13-15}$ At the same time mediators of inflammation such as tumor necrosis factor (TNF) $\alpha$, interleukin (IL)-1, and macrophage colony-stimulating factor increase binding of LDL to endothelium and smooth muscle and increases the transcription of the LDL-receptor gene. ${ }^{16,17} \mathrm{~A}$ vicious cycle of inflammation, modification of lipoproteins, and further inflammation is maintained in the artery by the presence of these lipids., ${ }^{2,18}$ Therefore drugs that simultaneously regulate lipid levels and reduce inflammation may have added benefits in the treatment of atherosclerosis.

Carrageenan is a polysaccharide used for inducing acute inflammation, which releases various inflammatory and proinflammatory mediators like leukotrienes, histamine, bradykinin, TNF- $\alpha$, prostaglandins etc. In this study fenofibrate showed a significant inhibition of paw oedema, comparable to aspirin, in carrageenan induced paw oedema model when compared to the control group. Acute inflammation shows a biphasic course. First phase begins with the release of serotonin, histamine and kinins after the injection of the phlogistic agent in the first few hours. However, in the second phase prostaglandin like substances are released two to three hours after carrageenan injection. $^{9}$

In the cotton pellet granuloma model of subacute inflammation, treatment with fenofibrate $(36 \mathrm{mg} / \mathrm{kg})$ exhibited a significant decrease in the mean granuloma weight when compared to the control group, though there was no significant difference between the aspirin and fenofibrate treated groups. Histopathology of haematoxylin and eosin stained sections of the grass pith induced granuloma showed abundant granulation tissue with densely scattered neutrophils and fibroblast in the control group but revealed reduced granulation tissue with few neutrophils and fibroblast in fenofibrate treated group.
To prevent cardiovascular disease and its complications, patients typically received hypolipidemics; however, the inflammatory arm of treatment has not received as much attention. In the Fenofibrate Intervention and Event Lowering in Diabetes (FIELD) study, fenofibrate showed a $11 \%$ reduction in total cardiovascular events (the composite of cardiovascular disease death, myocardial infarction, stroke, and coronary and carotid revascularisation), indicating that the addition of fenofibrate improves patient outcomes. ${ }^{19}$

Anti-inflammatory activity of fenofibrate observed in the present study may be attributed to its potential to suppress NF-kB activity and TGF-beta1 expression through PPAR$\alpha{ }^{20}$ Fenofibrate was also found to decrease hsCRP, TNF $\alpha$, IL-6, IL- $1 \beta$ and IFN- $\gamma$ levels in various studies. ${ }^{17,21}$ Fenofibrate reduced MCP-1 levels in patients with elevated LDL levels which predicts MI and mortality in patients with acute coronary syndromes. ${ }^{22}$

Observations of our study are in agreement with the earlier study reports stating that fenofibrate may have antiinflammatory activity. It appears that fenofibrate exerts its anti-inflammatory activity through PPAR $\alpha .{ }^{23}$ As discussed earlier, dyslipidemia induces inflammation. Therefore, lipid reduction may partly contribute to the antiinflammatory actions. ${ }^{24}$

\section{CONCLUSION}

In the treatment of atherosclerosis and its complications fenofibrate can be expected to have dual benefit by virtue of their hypolipidemic as well as anti-inflammatory effect. This study also suggests that these hypolipidemic agents will open new avenues in the management of a number of inflammatory diseases.

\section{Funding: No funding sources Conflict of interest: None declared \\ Ethical approval: The study was approved by the Institutional Animal Ethics Committee}

\section{REFERENCES}

1. Libby P. The pathogenesis, prevention and treatment of atherosclerosis. In: Fauci AS, Braunwald E, Kasper DL, Hauser SL, Longo DL, Jameson JL, et al. Harrison's Principles of internal medicine. $18^{\text {th }}$ Edition. New York: McGraw Hill Publishers; 2011:1983.

2. Ross R. Atherosclerosis - an inflammatory disease. N Engl J Med. 1999;340:115-26.

3. Libby P. Inflammation in atherosclerosis. Nature 2002;420:868-74.

4. Hansson GK. Inflammation, atherosclerosis, and coronary artery disease. N Engl J Med 2005;352:168595.

5. Desvergne B, Wahli W. Peroxisome proliferatoractivated receptors: nuclear control of metabolism. Endocr Rev. 1999;20:649-88. 
6. Staels B, Dallongeville J, Auwerx J, Schoonjans K, Leitersdorf E, Fruchart JC, et al. Mechanism of action of fibrates on lipid and lipoprotein metabolism. Circulation. 1998;98:2088-93.

7. Zhu S, Su G, Meng QH. Inhibitory effects of micronized fenofibrate on carotid atherosclerosis in patients with essential hypertension. Clin. Chem. 2006;52:2036-42.

8. Wang TD, Chen WJ, Lin JW, Cheng CC, Chen MF, Lee YT. Efficacy of fenofibrate and simvastatin on endothelial function and inflammatory markers in patients with combined hyperlipidemia: relations with baseline lipid profiles. Atherosclerosis. 2003;170:31523.

9. Turner RA. Screening Methods in Pharmacology. New York and London: Academic Press Inc; 1965.

10. Patil PA, Kulkarni DR. Effect of anti proliferative agents on healing of dead space wounds in rats. Ind $\mathrm{J}$ Med Res. 1984;74:445-7.

11. Staels B, Maes M, Zambon A. Fibrates and future PPAR alpha agonists in the treatment of cardiovascular disease. Nat Clin Pract Cardiovasc Med. 2008;5:542-53.

12. van der Wall AC, Becker AE, van der Loos CM, Das TK. Site of intimal rupture or erosion of thrombolised coronary atherosclerotic plaque is characterized by an inflammatory process irrespective of the dominant plaque morphology. Circulation. 1994;89:36-44.

13. Quinn MT, Parthasarathy S, Fong LG, Steinberg D. Oxidatively modified low density lipoproteins: a potential role in recruitment and retention of monocyte /macrophages during atherogenesis. Proc Natl Acad Sci USA. 1987;84:2995-8.

14. Rajavashisth TB, Andalibi A, Territo MC, Berliner JA, Navab M, Fogelman AM, et al. Induction of endothelial cell expression of granulocyte and macrophage colony-stimulating factors by modified low-density lipoproteins. Nature. 1990;344:254-7.

15. Leonard EJ, Yoshimura T. Human monocyte chemoattractant protein-1 (MCP-1). Immunol Today. 1990;11:97-101.

16. Stopeck AT, Nicholson AC, Mancini FP, Hajjar DP. Cytokine regulation of low density lipoprotein receptor gene transcription in HepG2 cells. J Biol Chem. 1993;268:17489-94.

17. Hajjar DP, Haberland ME. Lipoprotein trafficking in vascular cells: molecular Trojan horses and cellular saboteurs. J Biol Chem. 1997;272:22975-8.

18. Spagnoli LG, Bonanno E, Sangiorgi G, Mauriello A. Role of Inflammation in Atherosclerosis. J Nucl Med. 2007;48:1800-15.

19. Keech A, SimesRJ, Barter P, Best J, Scott R, Taskinen $\mathrm{M}$, et al. Effects of long-term fenofibrate therapy on cardiovascular events in 9795 people with type 2 diabetes mellitus (the FIELD study): randomised controlled trial. Lancet. 2005;366:1849-61.

20. Li L, Emmett N, Mann D, Zhao X. Fenofibrate attenuates tubulointerstitial fibrosis and inflammation through suppression of nuclear factor $-\kappa B$ and transforming growth factor- $\beta 1 / \mathrm{Smad} 3$ in diabetic nephropathy. Exp Biol Med. 2010;235(3):383-91.

21. Ye P, Li J J, Su G, Zhang C. Effects of fenofibrate on inflammatory cytokines and blood pressure in patients with hypertriglyceridemia. Clin. Chim. Acta. 2005;356:229-32.

22. Undas A, Lowenhoff CM, Domagala TB, Iwaniec T, Dropinski J, Lowenhoff T, et al. Early antithrombotic and anti-inflammatory effects of simvastatin versus fenofibrate in patients with hypercholesterolemia. Thromb. Haemost. 2005;94:193-9.

23. Brown JD, Plutzky J. Peroxisome proliferatoractivated receptors as transcriptional nodal points and therapeutic targets. Circulation. 2007;115:518-33.

24. Athyros VG, Kakafika AI, Karagiannis A, Mikhailidis DP. Do we need to consider inflammatory markers when we treat atherosclerotic disease? Atherosclerosis. 2008;200:1-12.

Cite this article as: Serah J, Torgal SS, Ramesh C, Anna M. Effect of fenofibrate on acute and subacute inflammation in male Wistar rats. Int J Basic Clin Pharmacol 2018;7:2190-5. 